to 15 December 1999.

Contact: HTC-6 Congress Secretariat, Ordibo bvba, Lucas Henninckstraat 20, B-2610 Wilrijk (Antwerp), Belgium; Tel.: +32 (3) 561 2831; Fax: +32 (3) 827 8439; e-mail: smitsr@ pophost.eunet.be; home page for updated program: http://www.ordibo.be/htc.

\section{World Congress of Food Science \& Technology, 3-8 October 1999, Sydney, Australia}

For further information contact: IUFoST Congress 10, P.O. Box 1493, North Sydney, NSW 2059, Sydney, Australia; Tel: +61 2 9959 4499; Fax: +61 29954 4327; E-mail: iufost10@alfst.asn.au; website: http:// alfst.asn.au

\section{Plutonium Futures-The Science, 10-14 July 2000, Santa Fe, New Mexico, USA}

This conference, the second in a series, is designed to be an interdisciplinary forum to present and discuss current research on physical and chemical properties of plutonium and other actinide elements. This forum will have international participation to discuss current and emerging science (chemistry, physics, materials science, nuclear science, and actinides in the environment) of actinides relevant to enhancing global nuclear security. Contact K. C. Kim, K. K. S. Pillay; Tel: +1 505667 7753; Fax: +1 505667 7966; E-mail: puconf2000@lanl.gov, http://www.lanl.gov/Pu2000. html.

\section{5th World Congress of Theoretically Oriented Chemists, (WATOC'99), 1-6 August 1999, Imperial College, London, UK}

For further information see the WATOC'99 web site: http://www.chemsoc.org/watoc'99/.

\section{International Symposium on Macrocyclic Chemistry (ISMC'99), 18-23 July 1999, Barcelona, Spain}

For further information see the ISMC'99 web site: http://www1.uji.es/ismc.

New Books and Publications

\section{New Publications from the World Health Organization}

\section{Concise International Chemical Assessment Documents (CICADs)}

Concise International Chemical Assessment Documents (CICADs) are the latest in a family of publications from the International Program on Chemical Safety (IPCS), a cooperative program of the World Health Organization (WHO), the International Labour Organisation (ILO), and the United Nations Environment Program (UNEP). CICADs join the Environmental Health Criteria documents (EHCs) as authoritative documents on the risk assessment of chemicals.

CICADs are concise documents that provide summaries of the relevant scientific information concerning the potential effects of chemicals upon human health and/or the environment. They are based on selected national or regional evaluation documents or on existing EHCs. Before acceptance for publication as CICADs by IPCS, these documents undergo extensive peer review by internationally selected experts to ensure their completeness, accuracy in the way in which the original data are represented, and the validity of the conclusions drawn.

The primary objective of CICADs is characterization of hazard and dose-response from exposure to a chemical. CICADs are not a summary of all available data on a particular chemical; rather, they include only that information considered critical for characterization of the risk posed by the chemical. The critical studies are, however, presented in sufficient detail to support the conclusions drawn. For additional information, the reader should consult the identified source documents upon which the CICAD has been based.

Risks to human health and the environment will vary considerably depending upon the type and extent of exposure. Responsible authorities are strongly encouraged to characterize risk on the basis of locally measured or predicted exposure scenarios. To assist the reader, examples of exposure estimation and risk characterization are provided in CICADs, whenever possible. These examples cannot be considered as representing all possible exposure situations, but are provided as guidance only. The reader is referred to EHC 170 for advice on the derivation of health-based guidance values. 